\title{
Message from the Editor-in-Chief regarding ethical violations
}

Recently two manuscripts were submitted to the Clinical Journal of Gastroenterology that contained possible acts of plagiarism. They were brought to the attention of the editors by CrossCheck, a similarity check and plagiarism detection tool, implemented into our Editorial Manager. Both manuscripts were finally judged to be plagiarism, and rejected at the time of peer review. In both manuscripts, the first authors were also the corresponding authors and were deemed mainly responsible for plagiarism. The journal has banned them from submitting to the journal for 1-2 years, depending on the degree of plagiarism.
The editors of the Clinical Journal of Gastroenterology abide by the recommendations formulated by the International Committee of Medical Journal Editors (http://www. icmje.org/) and take this issue very seriously. We are announcing this unfortunate incident to our authors and readers to raise awareness about publication ethics and integrity in academic publication.

Tetsuji Takayama

Editor-in-Chief 